Mеталлофиз. новейшие технол. / Metallofiz. Noveishie Tekhnol. (C) 2016 ИМФ (Институт металлофизики 2016, т. 38, № 9, сс. 1233-1247 / DOI: 10.15407/mfint.38.09.1233 им. Г. В. Курдюмова НАН Украины) Оттиски доступны непосредственно от издателя

Фотокопирование разрешено только

Напечатано в Украине.

в соответствии с лицензией

\title{
ФАЗОВЫЕ ПРЕВРАЩЕНИЯ
}

PACSnumbers:61.43.Dq, 64.70.pe,64.75.Nx, 71.15.Mb, 71.15.Pd,71.20.Be, 71.23.Cq,82.60.Lf

\section{Теоретична аналіза процесів фазоутворення в аморфних стопах системи $\mathrm{Fe}-\mathrm{Zr}$}

\author{
І. В. Плющай, Т. Л. Цареградська, О. О. Каленик, О. І. Плющай*
}

Київський національний університет імені Тараса Шевченка, вул. Володилирська, 64/13, 01601 Київ, Україна

"Iнститут металофізики іл. Г. В. Курдюлова НАН Украӥни, бульв. Акад. Вернадського, 36,

03142 Київ, Україна

\begin{abstract}
Аналізу фазових перетворень у системі Fe-Zr було проведено за допомогою $a b$ initio молекулярної динаміки та термодинамічного підходу. Представлено першопринципне моделювання методою молекулярної динаміки процесів аморфізації та кристалізації у системі Fe-Zr. Положення атомів у надкомірці $\mathrm{Fe}_{29} \mathrm{Zr}_{3}$ моделювалися шляхом числового відпалу методою функціоналу густини в узагальненому градієнтному наближенні. Обговорюються зміни густини електронних станів надкомірки $\mathrm{Fe}_{29} \mathrm{Zr}_{3}$ при рідинноаморфно-кристалічному фазовому переході. Найбільш помітною відмінністю між електронними спектрами рідкої й аморфної фаз є поява псевдощілини на рівні Фермі, що корелює з електронним критерієм термостабільности аморфних металевих стопів Нагеля-Таука. Подальший відпал в ізотермічно/ізоентальпійному ансамблі при більш високих температурах приводить до різкої зміни електронного спектра та перегрупування атомів, що ми приписуємо першій стадії кристалізації аморфного стопу. В рамках термодинамічного підходу було побудовано концентраційну залежність відносної інтегральної Гіббсової вільної енергії для вихідної аморфної фа-
\end{abstract}

Corresponding author: Inna Vyacheslavivna Plyushchay

E-mail: inna.plyushchay@gmail.com

Taras Shevchenko National University of Kyiv, 64/13 Volodymyrska Str., 01601 Kyiv, Ukraine

"G. V. Kurdyumov Institute for Metal Physics, N.A.S. of Ukraine,

36 Academician Vernadsky Blvd., UA-03142 Kyiv, Ukraine

I. V. Plyushchay, T. L. Tsaregrads'ka, O. O. Kalenyk, and O. I. Plyushchay, The Theoretical Analysis of Phase-Formation Processes in Amorphous Alloys of $\mathrm{Fe}-\mathrm{Zr}$ System, Metallofiz. Noveishie Tekhnol., 38, No. 9: 1233-1247 (2016) (in Ukrainian), DOI: 10.15407/mfint.38.09.1233. 
зи; ця залежність має специфічну S-подібну форму, що вказує на тенденцію стопів до фазового розшарування. Термодинамічна метода підтвердила, що процеси формування фаз у бінарних стопах системи $\mathrm{Fe}-\mathrm{Zr}$ проходять у 2 етапи: спочатку відбуваються процеси фазового розшарування на дві аморфні фази за типом спинодального розпаду, потім - кристалізації кожної аморфної фази. Розрахована концентраційна область аморфізації бінарних стопів системи $\mathrm{Fe}-\mathrm{Zr}$ добре узгоджується з експериментальними даними.

Ключові слова: фазові переходи, фазове розшарування, аморфні стопи, електронна структура, ab initio молекулярна динаміка, відносна інтегральна Гіббсова вільна енергія.

The thermodynamic and $a b$ initio molecular-dynamics approaches are applied to analyse the phase transitions in the $\mathrm{Fe}-\mathrm{Zr}$ system. First-principles molecular-dynamics simulations of the amorphization and crystallization processes in the $\mathrm{Fe}-\mathrm{Zr}$ system are presented. The atomic positions in the $\mathrm{Fe}_{29} \mathrm{Zr}_{3}$ supercell are modelled by simulating annealing with usage of the density functional theory in the generalized gradient approximation. Changes in the electron density of states for the $\mathrm{Fe}_{29} \mathrm{Zr}_{3}$ supercell under liquid-amorphous-crystalline phase transitions are discussed. The most marked difference between the electronic spectra of the liquid and amorphous phases is a pseudogap at the Fermi level that is consistent with the Nagel-Tauc electronic criterion of the amorphous metallic-alloy thermal stability. Further simulating annealing in the isothermal/isenthalpic ensemble under the higher temperatures leads to the drastically changes of the electronic spectrum and rearrangement of atoms, which we assign to the first stage of the amorphous-alloy crystallization. The concentration dependence of relative integral Gibbs' free energy for the initial amorphous $\alpha$-phase are constructed; this dependence has a specific S-shaped appearance (due to both the great value of relative volume change during the formation of the alloy and the negative value of entropy) that indicates a tendency of alloys to phase separation. The thermodynamic method confirms that the processes of phase formation in binary alloys of $\mathrm{Fe}-\mathrm{Zr}$ system pass in two stages: at first, the processes of phase separation into two amorphous phases by means of the spinodal mechanism are observed; then, each phase of amorphous ones resulting from separation begins to crystallise. The concentration area of amorphization of $\mathrm{Fe}-\mathrm{Zr}$ system alloys is calculated; the results are in a good agreement with experimental data.

Key words: phase transitions, phase separation, amorphous alloys, electronic structure, ab initio molecular dynamics, relative integral Gibbs' free energy.

Анализ фазовых превращений в системе $\mathrm{Fe}-\mathrm{Zr}$ был проведён с помощью $a b$ initio молекулярной динамики и термодинамического подхода. Представлено первопринципное моделирование методом молекулярной динамики процессов аморфизации и кристаллизации в системе $\mathrm{Fe}-\mathrm{Zr}$. Положения атомов в сверхъячейке $\mathrm{Fe}_{29} \mathrm{Zr}_{3}$ моделировались путём числового отжига методом функционала плотности в обобщённом градиентном приближении. Обсуждаются изменения плотности электронных состояний сверхъячейки $\mathrm{Fe}_{29} \mathrm{Zr}_{3}$ при жидкостно-аморфно-кристаллическом фазовом переходе. Наиболее заметным отличием между электронными спектрами жидкой и аморфной фаз является появление псевдощели на уровне Ферми, что кор- 
релирует с электронным критерием термостабильности аморфных металлических сплавов Нагеля-Таука. Дальнейший отжиг в изотермично/изоэнтальпийном ансамбле при более высоких температурах приводит к резкому изменению электронного спектра и перегруппировке атомов, которую мы приписываем первой стадии кристаллизации аморфного сплава. В рамках термодинамического подхода была построена концентрационная зависимость относительной интегральной свободной энергии Гиббса для исходной аморфной фазы; эта зависимость имеет специфическую Sобразную форму, что указывает на тенденцию сплавов к фазовому расслоению. Термодинамический метод подтвердил, что процессы формирования фаз в бинарных сплавах системы $\mathrm{Fe}-\mathrm{Zr}$ проходят в 2 этапа: сначала происходят процессы фазового расслоения на две аморфные фазы по типу спинодального распада, затем - кристаллизации каждой аморфной фазы. Рассчитанная концентрационная область аморфизации бинарных сплавов системы $\mathrm{Fe}-\mathrm{Zr}$ хорошо согласуется с экспериментальными данными.

Ключевые слова: фазовые переходы, фазовое расслоение, аморфные сплавы, электронная структура, ab initio молекулярная динамика, относительная интегральная свободная энергия Гиббса.

(Отрилано 30 травня 2016 р.)

\section{1. ВСТУП}

Стопи системи $\mathrm{Fe}-\mathrm{Zr}$ широко використовуються як функціональні матеріяли, особливо в атомній промисловості. Неіржавійні цирконійові сталі були розроблені для виготовлення контейнерів для зберігання відходів ядерної енергетики $[1,2]$ та матеріялів для ядерних реакторів та паливних елементів [3]. Пошук шляхів поліпшення функціональних властивостей матеріялів системи $\mathrm{Fe}-\mathrm{Zr}$ триває [4]. Одним із можливих шляхів модифікації властивостей матеріялів є зміна їх атомової структури, зокрема аморфізація. Відомо, що однорідність аморфних матеріялів поліпшує їхні функціональні властивості, наприклад, корозійну стійкість, механічні та магнетні властивості.

Тому є актуальними теоретичні дослідження процесів фазоутворення в стопах системи $\mathrm{Fe}-\mathrm{Zr}$, які дають змогу визначити оптимальний склад стопу, який можна аморфізувати, та передбачати можливі структурні зміни, що виникають при нагріванні аморфного стопу та приводять до зміни його фізичних властивостей.

\section{2. МОДЕЛЮВАННЯ МЕТОДОМ АВ ІNІТІО МОЛЕКУ ЛЯРНОЇ ДИНАМІКИ ПРОЦЕСІВ ФАЗОУТВОРЕННЯ В АМОРФНИХ СТОПАХ СИСТЕМИ $\mathrm{Fe}-\mathrm{Zr}$}

Методом ab initio молекулярної динаміки ми провели моделювання 
структури та електронних спектрів надкомірки $\mathrm{Fe}_{29} \mathrm{Zr}_{3}\left(C_{\mathrm{Zr}}=9,375\right.$ ат.\%) при рідинно-аморфно-кристалічному фазовому переході. Надкомірка вибрана таким чином, щоб вміст цирконію був близький до його вмісту в евтектичному стопі системи $\mathrm{Fe}-\mathrm{Zr}$ в області збагаченій залізом $\mathrm{Fe}-9,8$ ат.\% Zr. Як показують проведені експериментальні дослідження системи $\mathrm{Fe}-\mathrm{Zr}$ [5], добре аморфізуються стопи зі складом, близьким до евтектичного.

Розрахунок проводився методом функціоналу густини в узагальненому градієнтному наближенні [6] за допомогою пакета програм ABINIT [7].

Для числового моделювання процесу одержання аморфної фази з розтопу використовували надкомірку, що містить 32 атоми високотемпературної модифікації $\gamma$-Fе (ГЦК). Далі 3 атоми Fе були замінені на атоми $\mathrm{Zr}$ так, щоб останні були розташовані на максимально можливій відстані один від одного. Останнє необхідно для того, щоб уникнути кластеризації. Для релаксації внутрішніх напружень в надкомірці проведено числовий відпал положень атомів за алгоритмом, який описаний в [8]. При числовому відпалі відбувалася релаксація положень атомів у відповідності з силами, розрахованими з перших принципів. При цьому була дозволена зміна об'єму надкомірки зі збереженням її форми (кубічна). Цілком очікувано заміна трьох атомів $\mathrm{Fe}(z=26)$ на атоми $\mathrm{Zr}(z=40)$ приводить до збільшення об'єму вихідної надкомірки приблизно на 0,3\% .

Таким чином одержано вихідну «кристалічну» надкомірку $\mathrm{Fe}_{29} \mathrm{Zr}_{3}$ близького до евтектичного складу $\left(C_{\mathrm{Zr}}=9,375\right.$ ат. $\left.\%\right)$, що має ГЦК-структуру, як у високотемпературної модифікації $\gamma$-Fe. Зрозуміло, оскільки $\mathrm{Zr}$ не розчинний в $\mathrm{Fe}$ - це не є реально існуючий кристалічний твердий розчин або інтерметалева сполука. Найближчий стабільний інтерметалевий стоп - $\mathrm{Fe}_{2} \mathrm{Zr}$ [3]. Деякі дослідники повідомляють також про існування інтерметалевих стопів $\mathrm{Fe}_{23} \mathrm{Zr}_{6}$ та $\mathrm{Fe}_{3} \mathrm{Zr}$, але вони вважаються метастабільними [4]. Одержана вищезазначеним чином надкомірка, яку ми називаємо «кристалічною», необхідна для подальшого моделювання «рідкої» фази відповідного складу.

Електронний спектер вихідної «кристалічної» надкомірки $\mathrm{Fe}_{29} \mathrm{Zr}_{3}$ представлено на рис. $1, a$. Рівень Фермі тут і далі позначено вертикальною лінією. Видно, що ми маємо стандартний електронний спектер, характерний для кристалів з ГЦК-структурою, з деякою «тонкою структурою» (локальними максимумами та мінімумами) в околі рівня Фермі. При порівнянні одержаного спектру зі спектром інтерметаліду $\mathrm{Fe}_{2} \mathrm{Zr}$ можна помітити, що вищезазначена «тонка структура» електронного спектру наслідує основні особливості спектру інтерметаліду в околі рівня Фермі. Повна енергія та об'єм вихідної «кристалічної» надкомірки представлені на рис. 2 позначками ліворуч від нуля по осі абсцис. 
Для моделювання «рідкої» (розупорядкованої) фази ми провели числове нагрівання вихідної надкомірки методою ab initio молекулярної динаміки в канонічному $(N V T)$ ансамблі за температури 1600 К, близької до евтектичної. Енергетична залежність густини електронних станів «рідкої» фази представлена на рис. 1, б. Видно, що результатом ізотермічного відпалу за температури $1600 \mathrm{~K} \epsilon$ розмиття вищезгаданої «тонкої структури» в околі рівня Фермі. Також спостерігається цілком очікуване розширення електронної смуги на $\cong 9 \%$. Така модифікація електронного спектру є досить характерною при збільшенні температури. Наявність теплового хаотичного руху атомів призводить до розмиття та розширення електронних спектрів, оскільки термічні збурення положень атомів порушують близький порядок.

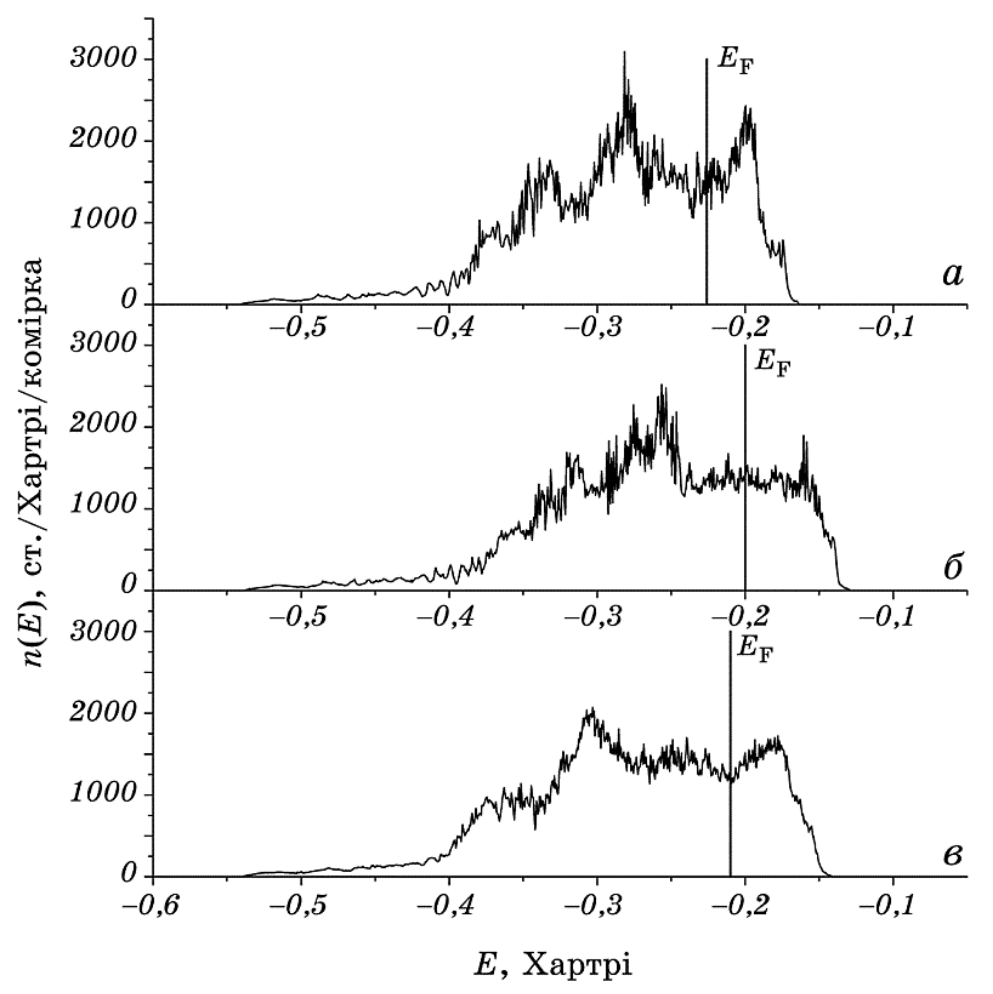

Pис. 1. Енергетична залежність густини електронних станів $\mathrm{Fe}_{29} \mathrm{Zr}_{3}: a-$ вихідна «кристалічна» надкомірка, б - розупорядкована «рідка» надкомірка, в - «аморфна» фаза. Вертикальною лінією позначено рівень Фермi.

Fig. 1. Energy dependence of the electron density of states of $\mathrm{Fe}_{29} \mathrm{Zr}_{3}$ : $a$-the original 'crystalline' supercell, $\sigma$-the disordered 'liquid' supercell, $\boldsymbol{B}$ 'amorphous' phase. Vertical line indicates the Fermi level. 
Для моделювання процесу аморфізації та кристалізації методою $a b$ initio молекулярної динаміки ми обрали ізотермічно/ізоентальпійний ансамбль, оскільки структурні фазові перетворення часто супроводжуються зміною власного об’єму. В процесі чисельного відпалу положень атомів в контакті з термостатом в нас була проведена повна оптимізація геометрії надкомірки: була дозволена як зміна об'єму, так і зміна форми надкомірки. Як початкову ми використовували надкомірку «рідкої» фази, одержану після ізотермічного відпалу за температури $1600 \kappa$, як найбільш розупорядковану (крок $N=1$ на рис. 2 ).

Зміну повної енергії та об'єму надкомірки при відпалі за температури $300 \mathrm{~K}$ представлено на рис. 2 . На початкових кроках молекулярної динаміки спостерігаються незначні коливання повної енергії надкомірки (непомітні в масштабі рис. 2), які не супроводжувались помітними змінами електронних спектрів. Далі спостерігається різке зменшення повної енергії надкомірки $(N=9$ на рис. 2), що супроводжується зменшенням об'єму надкомірки і помітною зміною її електронного спектру (рис. 1,6 ).

На рисунку 1, в представлена густина електронних станів надкомірки «аморфної» фази після відпалу при 300 К. Порівнюючи 3

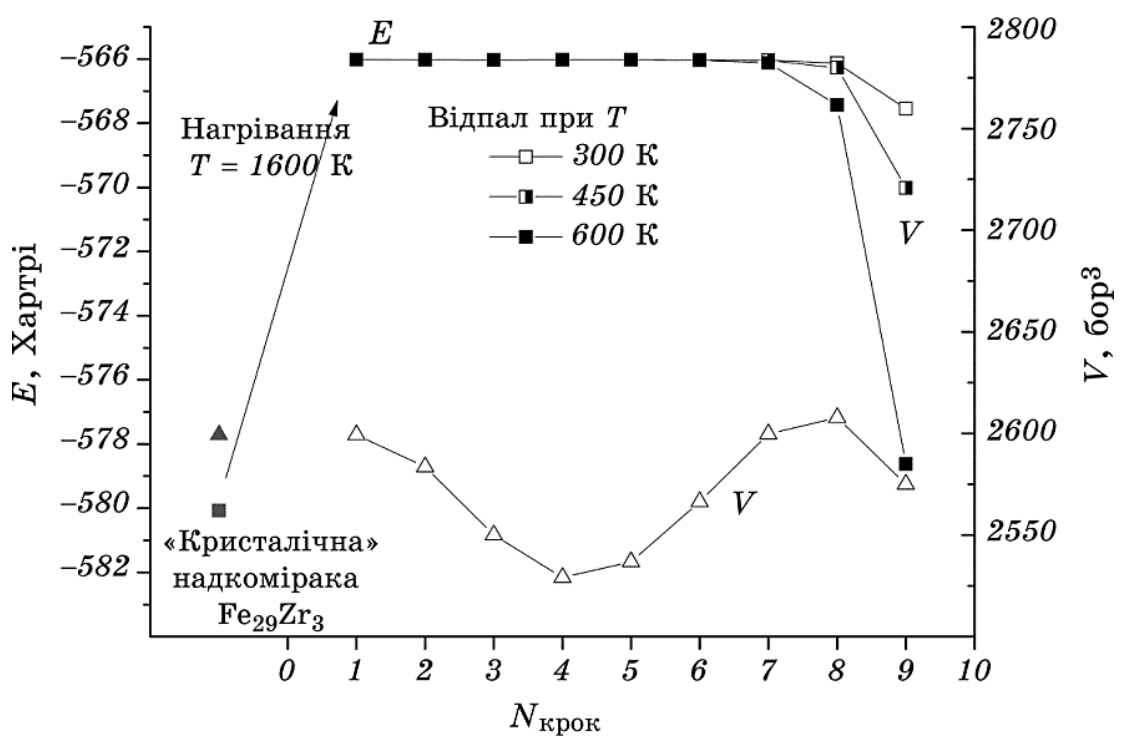

Рис. 2. Повна енергія електронної підсистеми $E$ (ліва шкала) та об'єм $V$ (права шкала) надкомірки $\mathrm{Fe}_{29} \mathrm{Zr}_{3}$. Вихідна «кристалічна» надкомірка представлена позначками ліворуч від нуля по осі абсцис.

Fig. 2. The total energy of electron subsystem $E$ (left scale) and volume $V$ (right scale) of $\mathrm{Fe}_{29} \mathrm{Zr}_{3}$ supercell. The original 'crystalline' supercell is represented by markers on the left side from zero on the horizontal axis. 
електронним спектром початкової «рідкої» фази (рис. 1, б), можна помітити появу локального мінімуму в околі рівня Фермі. Саме така, характерна при аморфізації [9], поведінка електронних спектрів і уможливлює нам називати одержану надкомірку «аморфною» фазою. Останнє корелює з експериментально одержаним критерієм стабільности аморфних металевих стопів Нагеля-Таука $[10,11]$ : зменшення густини електронних станів на рівні Фермі стабілізує аморфний стан.

Слід зазначити, що одержаний електронний спектер «аморфної» фази не співпадає з електронними спектрами стабільних кристалічних фаз системи $\mathrm{Fe}-\mathrm{Zr}$ за температури $300 \mathrm{~K}(\alpha-\mathrm{Fe}$ та інтерметалевого стопу $\mathrm{Fe}_{2} \mathrm{Zr}$ ). Якщо порахувати повну енергію суміші стабільних кристалічних фаз $\left(23(\alpha-\mathrm{Fe})+3\left(\mathrm{Fe}_{2} \mathrm{Zr}\right)=\mathrm{Fe}_{29} \mathrm{Zr}_{3}\right)$, що відповідає обраній нами надкомірці, то ми одержуємо величину $\cong-680$ Гартрі. Останнє, зрозуміло, набагато менше за повну енергію надкомірки одержаної «аморфної» фази, яка є метастабільною.

Треба зазначити, що при числовому відпалі за температури $300 \mathrm{~K}$ ми не спостерігали ознак кристалізації нашої системи: наприклад порядок взаємного розташування атомів у надкомірці не змінювався (атоми не переходили з однієї координаційної сфери в іншу). Останнє корелює з результатами експериментального вивчення процесу аморфізації та кристалізації в системі $\mathrm{Fe}-\mathrm{Zr}$ : в роботі [5] показано, що часовий відпал аморфного стопу $\mathrm{Fe}_{90} \mathrm{Zr}_{10}$ при температурах нижчих за 500 К не призводить до кристалізації.

Змоделювати процеси, схожі на кристалізацію аморфних стопів, вдалося при збільшенні температури числового відпалу нашої розупорядкованої надкомірки. Наприклад, при відпалі за температури 600 К спочатку спостерігається формування локального мінімуму в околі рівня Фермі, подібного до того, що обговорювався вище для «аморфної» фази. Потім спостерігається більш масштабна перебудова електронних спектрів (рис. 3), що супроводжується зміною порядку взаємного розташування атомів в надкомірці - перемішуються координаційні сфери. Така зміна порядку розташування атомів дозволяє говорити про початок кристалізаційних процесів у розглянутій структурі.

На рисунку 3 представлені енергетичні залежності густини електронних станів надкомірки $\mathrm{Fe}_{29} \mathrm{Zr}_{3}$, відпаленої за температур $300 \mathrm{~K}$ $(a), 450$ К (б) та 600 К (в). Видно, що при збільшенні температури числового відпалу електронний спектер системи зазнає значних змін. При подальшому збільшенні температури відпалу електронні спектри якісно не відрізняються від одержаного за температури 600 К (рис. 3, в). Якщо порівняти цей спектер зі спектром стабільної при зазначеній температурі фази $\alpha-\mathrm{Fe}$ (представлена на рис. 3 , 8 сірим кольором), то можна побачити, що три основних піка електронного спектру надкомірки після відпалу при 600 К в цілому від- 


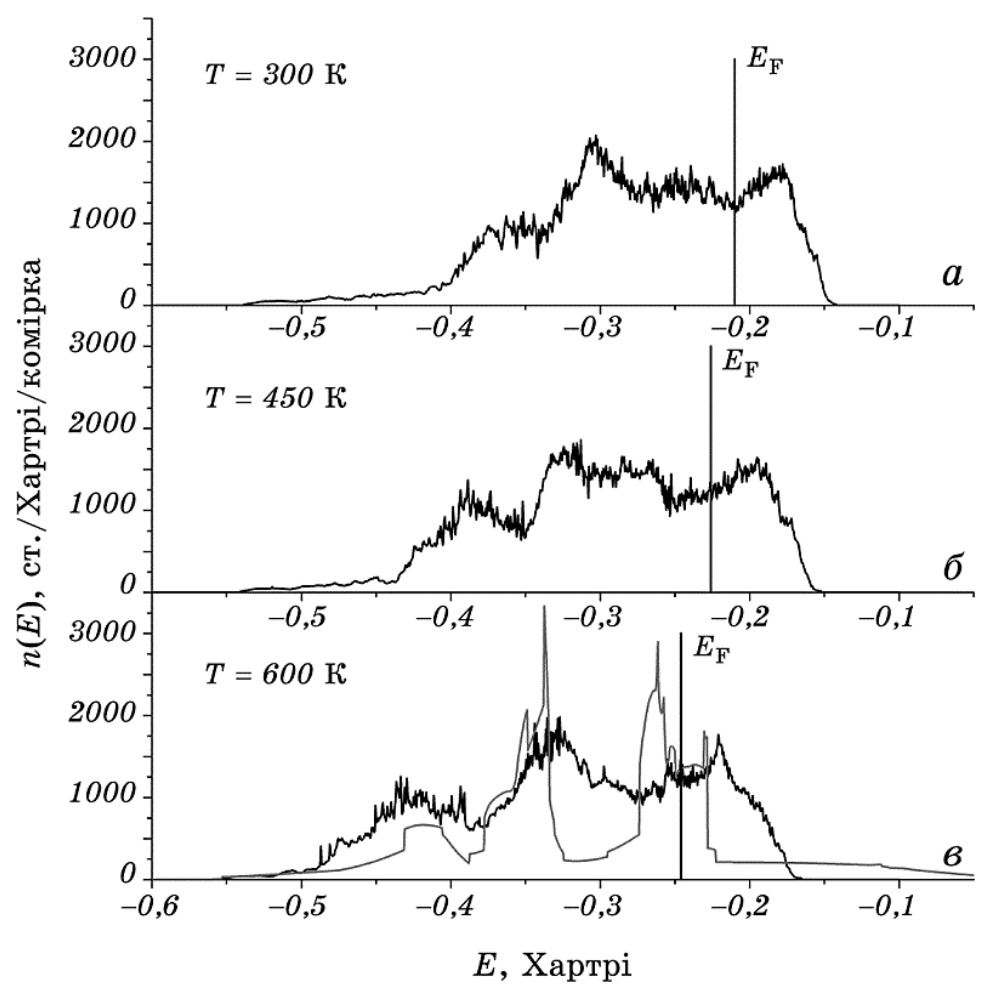

Рис. 3. Енергетична залежність густини електронних станів надкомірки $\mathrm{Fe}_{29} \mathrm{Zr}_{3}$ після відпалу за температур: $a-300 \mathrm{~K}, \sigma-450 \mathrm{~K}, \boldsymbol{\sigma}-600 \mathrm{~K}$. Сiрим кольором представлений електронний спектер $\alpha-F e$.

Fig. 3. Energy dependence of the electron density of states of $\mathrm{Fe}_{29} \mathrm{Zr}_{3}$ supercell after annealing at temperatures: $a-300 \mathrm{~K}, \sigma-450 \mathrm{~K}, 6-600 \mathrm{~K}$. The electronic spectrum of $\alpha-\mathrm{Fe}$ is presented in grey.

повідають основним трьом пікам $\alpha-\mathrm{Fe}$, але ширина цих піків значно більша (див. рис. 3, в).

Останне цілком зрозуміло, якщо взяти до уваги результати експериментальних досліджень процесу кристалізації аморфних стопів системи $\mathrm{Fe}-\mathrm{Zr}$ [5] - на першому етапі кристалізації формується перенасичений твердий розчин $\mathrm{Zr}$ в $\alpha$-Fe. Отже можна зробити висновок, що одержані електронні спектри відповідають нестабільній фазі - перенасиченому твердому розчину $\mathrm{Zr}$ в $\alpha$-Fe. Слід зазначити, що енергія одержаної "нестабільної кристалічної фази» (рис. 2) все ще набагато більша за повну енергію відповідної суміші стабільних фаз, розраховану вище.

Експериментальні дослідження [5] показали, що процеси фазоутворення в аморфних стопах системи $\mathrm{Fe}-\mathrm{Zr}$ проходять в два етапи: на першому відбувається фазове розшарування в межах аморфного 
стану за типом спинодального розпаду, на другому - кристалізація. Явище фазового розшарування не може бути змодельованим в межах $a b$ initio молекулярної динаміки розглянутої надкомірки і потребує застосування термодинамічного підходу.

\section{3. ТЕРМОДИНАМІЧНА АНАЛІЗА ПРОЦЕСІВ ФАЗОУТВОРЕННЯ В СТОПАХ СИСТЕМИ Fe-Zr}

Дослідженню процесів фазового розшарування в межах метастабільного аморфного стану останнім часом приділяється все більше уваги. Подібні дослідження дають змогу більш глибоко зрозуміти природу аморфного стану, а також оцінити, наскільки процеси фазового розшарування впливають на властивості аморфних стопів. Розглянемо термодинамічні передумови процесу фазового розшарування в аморфних бінарних стопах. Як і у випадку рідинних систем, можливість розшарування в аморфних стопах пов'язують 3 поведінкою концентраційної залежности відносної інтегральної Гіббсової вільної енергії. Для більшости бінарних аморфних стопів існує область концентрацій, в якій вільна енергія суміші двох аморфних фаз менша, ніж для однієї аморфної фази. У цій області концентрацій для деяких аморфних металевих стопів спостерігається фазове розшарування, яке відбувається за типом спинодального розпаду без зародження кристалів. Цей процес є особливим випадком початкової стадії фазового перетворення, коли система переходить в лабільний, тобто нестійкий щодо флуктуацій густини та складу стан, при цьому релаксація системи супроводжується посиленням флуктуацій концентрації компонентів. Для бінарних систем є область нестійких однорідних станів; порушення стійкости відбувається по відношенню до локальних відхилів від рівноважної концентрації. Якщо випадкові неоднорідності складу не зникають, а посилюються реакцією системи, це відповідає від'ємному коефіцієнту дифузії, тобто виникає явище висхідної дифузії. Для бінарних систем поява дифузійної нестійкости передує механічній нестійкості.

Термодинамічною передумовою розшарування в бінарних системах вважається $S$-подібна форма концентраційної залежности відносної Гіббсової вільної енергії $\Delta G(c, T)=\Delta H(c, T)-T \Delta S(c, T)$ [12]. Для більшости аморфних стопів відносна інтегральна ентальпія $\Delta H(c, T)$ має велике від'ємне значення та слабо змінюється в залежності від температури, проте величина відносної інтегральної ентропії $\Delta S(c, T)$ може мати також велике від'ємне значення за рахунок залежности $\Delta S(c, T)$ не тільки від концентрації, але і від зміни об'єму $\Delta V(c, T) / V_{0}$ при утворенні стопу [13]. Отже, конкурувальна поведінка величин $\Delta H(c, T)$ та $\Delta S(c, T)$ приводить до того, що концентраційна залежність $\Delta G(c, T)$ набуває $S$-подібної форми, що віддзеркалює тенденцію стопу до розшарування. 


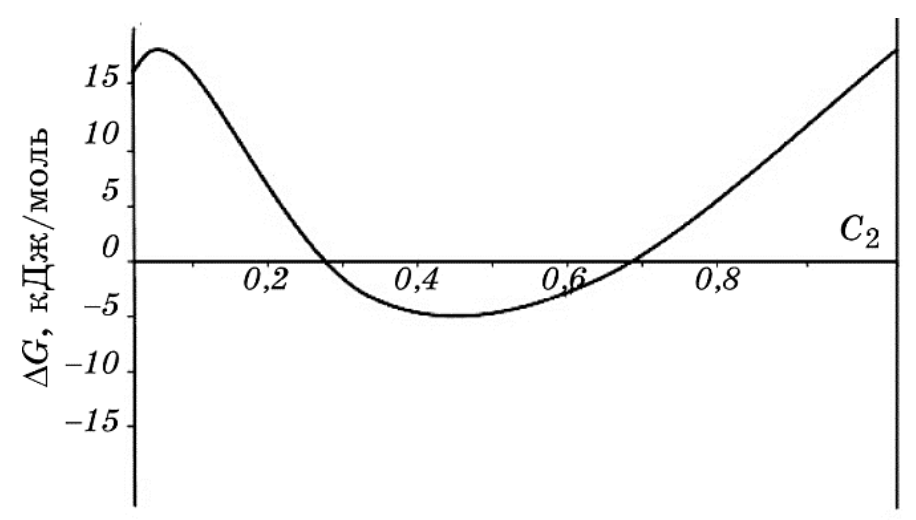

Рис. 4. Концентраційна залежність відносної інтегральної Гіббсової вільної енергії для початкової аморфної $\alpha$-фази для системи $\mathrm{Fe}-\mathrm{Zr}$.

Fig. 4. The concentration dependence of relative integral Gibbs free energy for the initial amorphous $\alpha$-phase of $\mathrm{Fe}-\mathrm{Zr}$ system.

Експерименти по низькотемпературним відпалам стопів системи $\mathrm{Fe}-\mathrm{Zr}$ показали, що при нагріванні відбувається розшарування в межах аморфного стану: спочатку виділяються 2 аморфні фази 3 концентрацією цирконію $5 \%$ і $20 \%$ відповідно (позначимо їх $\beta$ і $\delta$ ), потім на фоні цих фаз утворюються 2 кристалічні фази: розчин Zr в $\alpha-\mathrm{Fe}$ та хемічна сполука $\mathrm{Fe}_{3} \mathrm{Zr}$ (позначимо їх $\gamma$ i $\varepsilon$ ) [4].

На рисунку 4 наведено концентраційну залежність відносної інтегральної Гіббсової вільної енергії $\Delta G\left(C_{2}, T\right)$ для початкової аморфної $\alpha$-фази, розраховану згідно рівнянь, одержаних в роботі [13]. Концентраційна залежність відносної інтегральної Гіббсової вільної енергії початкової аморфної має специфічний $S$-подібний вигляд (за рахунок великого значення $\Delta V(c, T) / V_{0}$ та від'ємного значення $\Delta S(c, T))$, що вказує на схильність стопу до розшарування.

На рисунку 5 наведено результати розрахунків температурних залежностей загальної об'ємної частки кристалічної фази $X(T)$ та об'ємних часток аморфних та кристалічних фаз $X_{i}(T)$, що утворюються в процесі нагрівання аморфного стопу $\mathrm{Fe}_{90} \mathrm{Zr}_{10}$, проведених за допомогою рівнянь, одержаних в роботі [14]. Розрахунки показали, що за температури $550 \mathrm{~K}$ відбувається розшарування в межах аморфного стану: виділяються 2 аморфні фази з різною концентрацією цирконію. При подальшому нагріванні кожна з аморфних фаз, що утворились в результаті розшарування, починає кристалізуватись, при цьому частка аморфної фази в зразку зменшується. Розрахунки параметрів кінетики кристалізації показали, що процес кристалізації стопу $\mathrm{Fe}_{90} \mathrm{Zr}_{10}$ проходить в дві стадії у відповідності до діяграми стану бінарної системи $\mathrm{Fe}-\mathrm{Zr}$. За температури 600 К кристалізується розчин цирконію в $\alpha$-залізі, при цьому зростає концентрація 


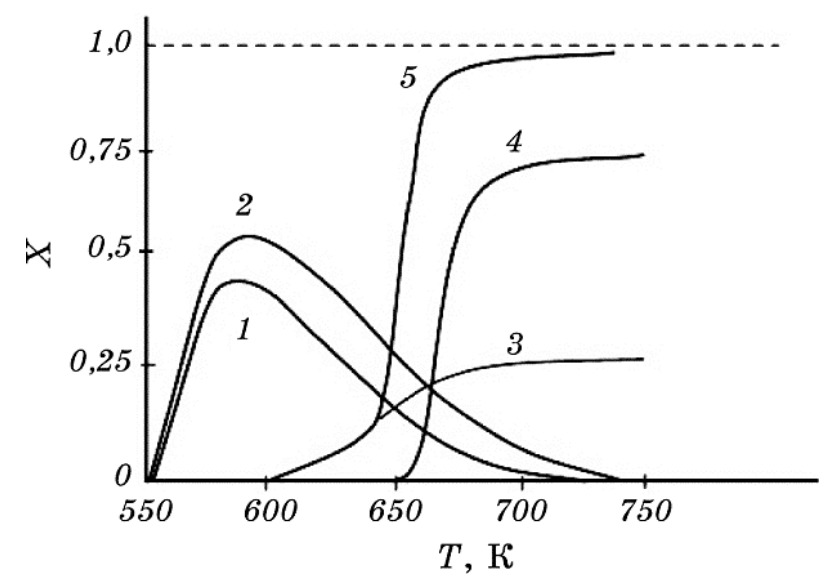

Рис. 5. Температурна залежність об'ємних часток фаз $X_{i}$, які з'являються в процесі неперервного нагрівання аморфного стопу $\mathrm{Fe}_{90} \mathrm{Zr}_{10}: 1$ - частка аморфної $\beta$-фази $X_{\beta}, 2$ - частка аморфної $\delta$-фази $X_{\delta}, 3$ - частка кристалічної $\gamma$-фази $X_{\gamma}, 4$ - частка кристалічної $\varepsilon$-фази $X_{\varepsilon}, 5$ - загальна об'ємна частка кристалічної фази $X(T)$.

Fig. 5. The temperature dependence of volume part of phases $X_{i}$, appearing at the continuous heating of amorphous $\mathrm{Fe}_{90} \mathrm{Zr}_{10}$ alloy: 1 -part of amorphous $\beta$ phase $X_{\beta}, 2$-part of amorphous $\delta$-phase $X_{\delta}, 3$-part of crystalline $\gamma$-phase $X_{\gamma}$, 4 -part of crystalline $\varepsilon$-phase $X_{\varepsilon}, 5$-total volume part of crystalline phase $X(T)$.

цирконію в аморфній матриці. При подальшому нагріванні за температури 650 К починається кристалізація твердого розчину цирконію та заліза в хемічній сполуці $\mathrm{Fe}_{3} \mathrm{Zr}$. Теоретична інтегральна крива температурної залежности об'ємної частки кристалічної фази $X(T)$ характеризується наявністю «полички», яка свідчить про двостадійність процесу кристалізації.

Розглянемо закономірності кінетики кристалізації в високотемпературній області, які визначають можливості одержання стопів системи $\mathrm{Fe}-\mathrm{Zr}$ в аморфному стані. На рисунку 6 наведено результати теоретичних розрахунків, проведених в рамках модифікованої теорії гомогенної нуклеації [14], для температурної залежности об'ємної частки кристалічної фази $X(T)$, яка відображає кінетику фазоутворення стопу із початковою концентрацією цирконію $C_{\mathrm{Zr0}}=$ $=10$ ат. $\% \mathrm{Zr}$ при швидкості гартування $d T / d t=10^{6} \mathrm{~K} / \mathrm{c} .3$ рисунку 6 видно, що область інтенсивної кристалізації $T=600-700 \mathrm{~K}$ лежить у вузькому температурному інтервалі $\Delta T \cong 100 \mathrm{~K}$, загальна об'ємна частка кристалічної фази при цьому складає $X=10^{-12}$, тобто загартування дає змогу фіксувати аморфний стан стопу, оскільки загальний критерій аморфного стану: $X \leq 10^{-6}$.

Результати розрахунків по визначенню области концентрації 


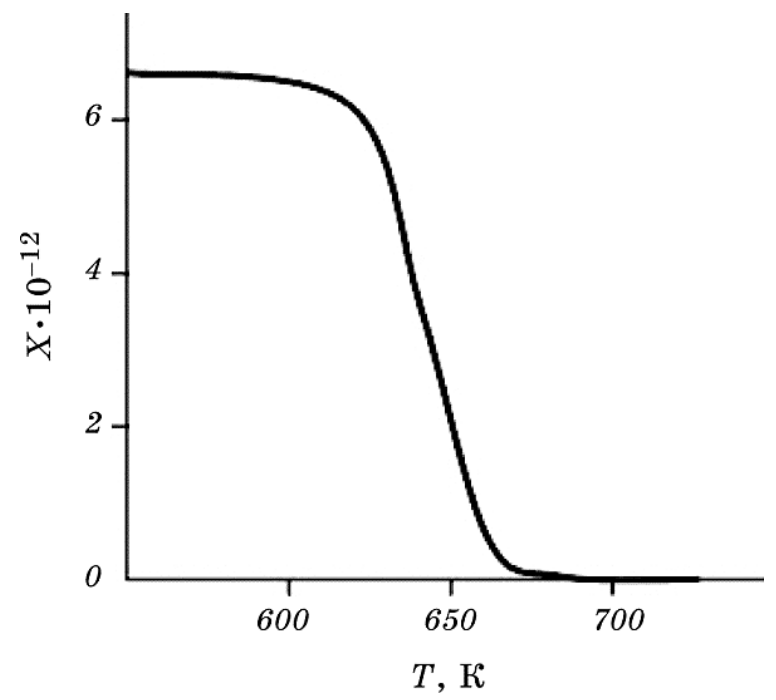

Рис. 6. Кінетика кристалізації стопів системи $\mathrm{Fe}-\mathrm{Zr}$ з початковою концентрацією цирконію $C_{\mathrm{Zr0}}=10$ ат. $\% \mathrm{Zr}$.

Fig. 6. Crystallization kinetics of alloys $\mathrm{Fe}-\mathrm{Zr}$ system with initial concentration of zirconium $C_{\mathrm{Zr} 0}=10$ at. $\% \mathrm{Zr}$.

$C_{\mathrm{Zr0}}$, в якій загартування утворює аморфний стан стопу, наведено на рис. 7. Аналіза результатів розрахунків, представлених на рис. 7, дає змогу дійти висновку, що область аморфізації стопів системи $\mathrm{Fe}-\mathrm{Zr}$ знаходиться в межах 3-15 ат.\% цирконію, що добре узгоджується з експериментальними даними.

\section{4. ВИСНОВКИ}

Таким чином, методою першопринципної молекулярної динаміки було проведене числове відтворення реального процесу аморфізації та кристалізації металевих стопів з контролем зміни електронних спектрів на прикладі системи $\mathrm{Fe}-\mathrm{Zr}$. Основною відмінністю електронного спектру одержаної «аморфної» фази в порівнянні зі спектром «рідкої» надкомірки є локальний мінімум, що формується в околі рівня Фермі. Останне корелюе з експериментально одержаним критерієм стабільности аморфних металевих стопів НагеляТаука [10]. При збільшенні температури числового відпалу спостерігається кристалізація системи, що супроводжується зміною порядку розташування атомів та значною перебудовою електронного спектру. Останній відповідає електронному спектру перенасиченого твердого розчину $\mathrm{Zr}$ в $\alpha-\mathrm{Fe}$, що дійсно формується на першому етапі кристалізації аморфних стопів системи $\mathrm{Fe}-\mathrm{Zr}$. 


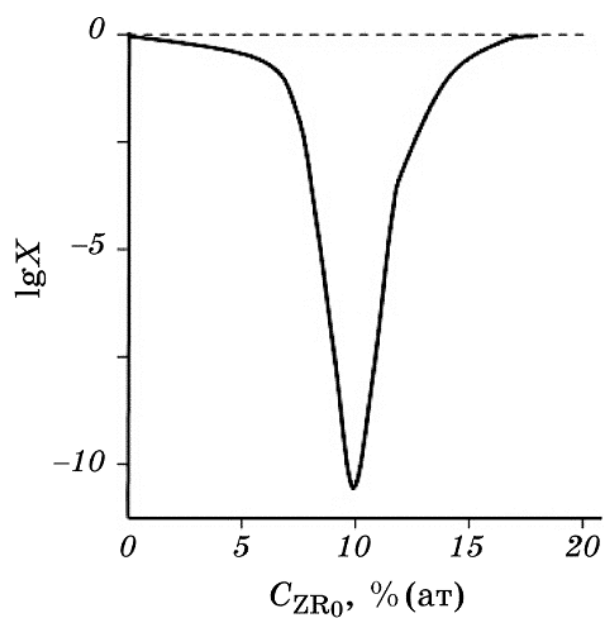

Рис. 7. Концентраційна залежність об’ємної частки кристалічної фази в системі $\mathrm{Fe}-\mathrm{Zr}$ за швидкости гартування у $10^{6} \mathrm{~K} / \mathrm{c}$.

Fig. 7. The concentration dependence of volume part of crystalline phase in $\mathrm{Fe}-\mathrm{Zr}$ system at quenching speed of $10^{6} \mathrm{~K} / \mathrm{s}$.

Далі термодинамічною методою було підтверджено, що процеси фазоутворення в бінарних стопах системи проходять в 2 етапи: спочатку відбуваються процеси фазового розшарування на дві аморфні фази за типом спинодального розпаду, потім - кристалізації кожної аморфної фази. За допомогою розрахунків, проведених в рамках модифікованої теорії гомогенної нуклеації для бінарних систем показано, що процес кристалізації бінарних аморфних стопів системи $\mathrm{Fe}-\mathrm{Zr}$ є двостадійним: спочатку кристалізується твердий розчин $\mathrm{Zr}$ в $\alpha$-Fe, потім хемічна сполука $\mathrm{Fe}_{3} \mathrm{Zr}$. Показано, що область аморфізації бінарних стопів системи $\mathrm{Fe}-\mathrm{Zr}$ знаходиться в межах 3-15 ат.\% цирконію, що добре узгоджується з експериментальними даними.

\section{ЦИТОВАНА ЛІТЕРАТУРА}

1. S. M. McDeavitt, D. P. Abraham, J. Y. Park, and D. D. Keiser, JOM, 49: 29 (1997).

2. S. M. McDeavitt, D. P. Abraham, and J. Y. Park, J. Nucl. Mater., 257: 21 (1998).

3. M. S. Granovsky and D. Arias, J. Nucl. Mater., 229: 29 (1996).

4. F. Stein, G. Sauthoff, and M. Palm, J. Phase Equilibria, 23: 480 (2002).

5. Г. Е. Абросимова, А. С. Аронин, Физика твёрдого тела, 40, № 10: 1768 (1998).

6. J. P.Perdew, K. Burke, and M. Ernzerhof, Phys. Rev. Lett., 77: 3865 (1996).

7. X. Gonzea, B. Amadond, P.-M. Angladee, J.-M. Beukena, F. Bottind, 
P. Boulangera, F. Brunevalq, D. Calistej, R. Caracasl, M. Côtéo, T. Deutschj, L. Genovesei, Ph. Ghosezk, M. Giantomassia, S. Goedeckerc, D. R. Hamannm, P. Hermetp, F. Jolletd, G. Jomardd, S. Lerouxd, M. Mancinid, S. Mazevetd, M. J. T. Oliveiraa, G. Onidab, Y. Pouillona, T. Rangela, G.-M. Rignanesea, D. Sangallib, R. Shaltafa, M. Torrentd, M. J. Verstraetea, G. Zerahd, and J. W. Zwanzigerf, Computer Phys. Comm., 180: 2582 (2009).

8. H. B. Schlegel, J. Comput. Chem., 3: 214 (1982).

9. K. V. Ashok, P. Modak, A. Svane, and N. E. Christensen, Phys. Rev. B, 83: 134205 (2011).

10. S. R. Nagel, G. B. Fisher, G. Tauc, and B. G. Bardley, Phys. Rev. B, 13: 3284 (1976).

11. O. I. Nakonechnaya, I. V. Plyushchai, M. P. Semen'ko, and N. I. Zakharenko, Physics of Metals and Metallography, 90, No. 5: 439 (2000).

12. В. И. Лысов, Т. Л. Цареградская, О. В. Турков, Г. В. Саенко, В. В. Яриш, Журнал физической хилии, 81, № 10: 1765 (2007).

13. В. І. Лисов, Т. Л. Цареградська, О. В. Турков, Г. В. Саєнко, В. В. Яриш, Журнал фізичних досліджень, 12, № 3: 5 (2008).

14. Ю. А. Куницкий, В. И. Лысов, Т. Л. Цареградская, В. Е. Федоров, О. В. Турков, Металлофиз. новейшие технол., 25, № 12: 1563 (2003).

\section{REFERENCES}

1. S. M. McDeavitt, D. P. Abraham, J. Y. Park, and D. D. Keiser, JOM, 49: 29 (1997).

2. S. M. McDeavitt, D. P. Abraham, and J. Y. Park, J. Nucl. Mater., 257: 21 (1998).

3. M. S. Granovsky and D. Arias, J. Nucl. Mater., 229: 29 (1996).

4. F. Stein, G. Sauthoff, and M. Palm, J. Phase Equilibria, 23: 480 (2002).

5. G. E. Abrosimov and A. S. Aronin, Fizika Tverdogo Tela, 40, No. 10: 1768 (1998) (in Russian).

6. J. P.Perdew, K. Burke, and M. Ernzerhof, Phys. Rev. Lett., 77: 3865 (1996).

7. X. Gonzea, B. Amadond, P.-M. Angladee, J.-M. Beukena, F. Bottind, P. Boulangera, F. Brunevalq, D. Calistej, R. Caracasl, M. Côtéo, T. Deutschj, L. Genovesei, Ph. Ghosezk, M. Giantomassia, S. Goedeckerc, D. R. Hamannm, P. Hermetp, F. Jolletd, G. Jomardd, S. Lerouxd, M. Mancinid, S. Mazevetd, M. J. T. Oliveiraa, G. Onidab, Y. Pouillona, T. Rangela, G.-M. Rignanesea, D. Sangallib, R. Shaltafa, M. Torrentd, M. J. Verstraetea, G. Zerahd, and J. W. Zwanzigerf, Computer Phys. Comm., 180: 2582 (2009).

8. H. B. Schlegel, J. Comput. Chem., 3: 214 (1982).

9. K. V. Ashok, P. Modak, A. Svane, and N. E. Christensen, Phys. Rev. B, 83: 134205 (2011).

10. S. R. Nagel, G. B. Fisher, G. Tauc, and B. G. Bardley, Phys. Rev. B, 13: 3284 (1976).

11. O. I. Nakonechnaya, I. V. Plyushchai, M. P. Semen'ko, and N. I. Zakharenko, Physics of Metals and Metallography, 90, No. 5: 439 (2000).

12. V. I. Lysov, T. L. Tsaregradskaya, O. V. Turkov, G. V. Saenko, and V. V. Yarysh, Zhurnal Fizicheskoy Khimii, 81, No. 10: 1765 (2007) (in Russian). 
13. V. I. Lysov, T. L. Tsaregrads'ka, O. V. Turkov, G. V. Saenko, and V. V. Yarysh, Zhurnal Fizychnykh Doslidzhen', 12, No. 3: 5 (2008) (in Ukrainian).

14. Yu. A. Kunits'ky, V. I. Lysov, T. L. Tsaregrads'ka, V. Ye. Fedorov, and O. V. Turkov, Metallofiz. Noveishie Tekhnol., 25, No. 12: 1563 (2003) (in Russian). 